\title{
An Effective Pillared South African Bentonite Clay: Synthesis and Application as Green Chemistry Catalyst for Wastewater Treatment
}

\author{
S.J Baloyi ${ }^{\text {a, b }}$, J.A Moma ${ }^{a}$ and T.A Ntho ${ }^{\text {b }}$
}

\begin{abstract}
Natural bentonite clay from South Africa was used in preparation of pillared clay by the use of mixed oxide pillars of aluminium and zirconium. Ultrasonic treatment during the aging and intercalation steps was in the preparation of the composite $\mathrm{Al} / \mathrm{Zr}$-pillared bentonite clay. Application of ultrasonic treatment during both the aging and intercalation steps of the pillaring solution in the preparation process considerably decreases the processing time and the amount of water required compared with the conventional preparation method. The effect of ultrasonic treatment time $(5,10$ and $20 \mathrm{~min}$ ) on the structure and properties of the $\mathrm{Al} / \mathrm{Zr}$-pillared bentonite clay was studied. The obtained materials were characterized by powder X-ray diffraction (XRD), high-resolution scanning electron microscopy (HRSEM), energy dispersive spectroscopy (EDS) and nitrogen adsorption (BET surface area). The catalytic activities of these materials in the catalytic wet air oxidation (CWAO) of phenol shown that the ultrasonic treatment time is critical to the performance of the catalysts. The optimum results were obtained after ultrasonic treatment up to 10 minutes. Longer ultrasonic treatment times resulted in partial damage of the pillared clay structure. The conversion of phenol was found to be slightly affected by ultrasonic treatment times, although the pillared clays with short processing times ( 5 and $10 \mathrm{~min}$ ) performed slightly better.
\end{abstract}

Keywords-Al/Zr pillared clay, ultrasonic treatment, phenol, catalytic wet air oxidation.

\section{INTRODUCTION}

The worldwide demand for the industrial phenol market has gradually increased over the last decades due to the demand for its derivatives from the end-use segment [1]. Phenol and phenolic substances are discharged into water bodies from several industries, such as phenolic resin and pharmaceutical, petrochemical plants, oil refineries, steel plants, ceramic plants, coal conversion processes and pesticides manufacturing [2]. Many of the materials produced by the phenol industry are toxic and cannot be discharged into water bodies without

Manuscript received October 11,2017. This work was supported in part by the S.A. Department of Science and Technology and Mintek under Grant 96719 and ADR 31802, respectively.

S.J Baloyi is with the Molecular Science Institute, School of Chemistry, University of the Witwatersrand, P/Bag 3, WITS 2050, Johannesburg, South Africa and Advanced Materials Division, Advanced Materials Division, Mintek, Private Bag X3015, Randburg 2125; RSA (e-mail: jeffreyb@ mintek.co.za).

J. A. Moma is with the Molecular Science Institute, School of Chemistry, University of the Witwatersrand, RSA (e-mail: john.moma@wits.ac.za).

T.A Ntho is with the Advanced Materials Division, Mintek, Private Bag X3015, Randburg 2125; RSA (e-mail: thabangnt @ mintek.co.za). treatment. Wastewater containing phenol has received increased attention because of it's extremely toxicity to the aquatic life and resistance to biodegradation [3-5]. Therefore, removal or conversion of phenol organic compounds into environmentally harmless species is a current need.

Several technologies have been established to treat wastewater effluent containing phenol before its release into water streams, including extraction, adsorption (e.g. using activated carbon), biological, chemical oxidation and electrochemical techniques. However, these technologies cannot be used as effective methods due to severe limitations associated with high operating costs, formation of hazardous by-products, low conversion and applicability to a limited concentration range [6].

Recently, numerous studies have focused on alternative treatment methods, which are direct and effective, for removal of phenol from wastewater. Advanced oxidation processes (AOPs) can be a useful option, as many researches have shown that non-biodegradable wastewater such as phenol wastewater can be mineralized completely into $\mathrm{CO}_{2}, \mathrm{H}_{2} \mathrm{O}$ and other non-toxic inorganic compounds. The efficiency of AOPs results from the fact that the in-situ generated hydroxyl radicals $(\bullet \mathrm{OH})$ are highly reactive species $(\mathrm{E} 0=+2.8 \mathrm{~V})$, which attack the majority of organic molecules causing their oxidation to other products and ultimately to $\mathrm{CO}_{2}$ and $\mathrm{H}_{2} \mathrm{O}$ [6] and dilute inorganic acids [7]. Advanced oxidation processes include wet air oxidation (WAO), catalytic wet air oxidation (CWAO), $\mathrm{H}_{2} \mathrm{O}_{2}$-promoted catalytic wet air oxidation $\left(\mathrm{H}_{2} \mathrm{O}_{2}\right.$-CWAO) and Fenton process [8]. Among them, CWAO is the promising effective method for future industrial usage, because of its suitability for technologically economical and high conversion of phenol wastewater [9].

Numerous solid materials have been employed as catalyst in CWAO, such as supported copper oxide, manganese-cerium mixed oxide, aluminum hydroxide, zirconium hydroxide and carbon-supported metal oxides [10-12]. However, it is not cost-effective to use noble metal oxides, pure metal oxides/hydroxides for practical phenol wastewater removal. In contrary, layered clay minerals intercalated by inorganic metal polyhydroxycations with the abundant, low-cost and eco-friendly clay minerals show a great potential for use as CWAO catalyst. These solid catalysts are recognized as the 
materials of the 21 st century because of their abundant availability, inexpensiveness, environmental friendliness, high thermal stability, porosity, increased surface area and basal spacing, high adsorption capacity and catalytic activity for various refractory organic pollutants [13-16]. Therefore, due to these characteristics, research on preparation of pillared interlayered clays (PILCs) has attracted much attention recently.

The conventional preparation of PILCs involves long periods of time (1-5 days) and large amount of water, and such requirements represent a considerable shortcoming when trying to scale-up the pillaring process to industrial scale [7]. Therefore, the use of PILCs as heterogenous solids catalysts has not been escalated to commercial levels, due to the fact that it has been challenging to perform the conventional laboratory preparations method at industrial scale [17]. This is mainly due to the large volumes of water required during the preparation process and prolonged times. In order to reduce the large volume of water required, currently the pillaring method is focused on application of concentrated clay suspension, dry clay and concentrated pillaring agent solution [18]. Similarly, direct addition of clay to pillaring solutions decreases the time required for the preparation process and methods such as ultrasound [18] , microwave [19] and one-step high-temperature [20] have recently emerged as powerful and green approaches for synthesis of PILCs.

Therefore, in this work, the preparation of $\mathrm{Al} / \mathrm{Zr}$-pillared bentonites was carried out via ultrasound treatment during both the aging and the intercalation of the pillaring solution. Moreover, during the intercalation stage, dry clay was added directly to pillaring solutions. The effect of the variation of ultrasonic treatment time $(5,10$ and $20 \mathrm{~min})$ on the structure and physiochemical properties as well as the catalytic activity of the solids was studied.

\section{EXPERIMENTAL}

\section{A. Materials and Chemicals}

The bentonite clay mined by ECCA Holdings (Pty) Ltd., from Cape Town, South Africa was used as starting material for the preparation of $\mathrm{Al} / \mathrm{Zr}$ pillared bentonites. The natural bentonite clay was used without any further purification or cation exchange, sieving or refining. Analytical grade $\mathrm{Al}\left(\mathrm{NO}_{3}\right)_{3}$. $9 \mathrm{H}_{2} \mathrm{O}, \mathrm{Zr}\left(\mathrm{NO}_{3}\right)_{4} .5 \mathrm{H}_{2} \mathrm{O}, \mathrm{HCl}$ and $\mathrm{NaOH}$ used for preparation of pillaring agents and pillared bentonite were purchased from Merck Chemicals (Pty) Ltd and were used without further purification. The phenol used for catalytic experiments was purchased from Sigma Aldrich Chemical Co. Acetic acid and methanol of chromatographic grade was obtained from Merck. Calibration solutions were prepared from standard stock solutions by dilution. High purity water (resistivity 18.2 $\mathrm{M} \Omega \mathrm{cm}$ ) purified by a Milli-Q water system (millipore) in the laboratory was used throughout.

\section{B. Preparation of Pillaring Agents}

The mixed $\mathrm{Al} / \mathrm{Zr}$ - pillaring agent was prepared as follow: $\mathrm{NaOH}(0.4 \mathrm{M})$ solution was added to $\mathrm{Al} / \mathrm{Zr}(0.4 \mathrm{M})$ solutions at ratio of $3 / 1$. Our preliminary study found the $\mathrm{Al} / \mathrm{Zr}$ ratio of $3: 1$ to be the optimum for the catalytic activity of $\mathrm{Al} / \mathrm{Zr}$-pillared bentonite. And this ratio was therefore used in this study. The $\mathrm{NaOH}(0.4 \mathrm{M})$ was added under vigorous stirring until an $\left[\mathrm{OH}^{-}\right] /\left[\mathrm{Al}^{3+}+\mathrm{Zr}\right]$ molar ratio of $2: 1$ was reached. The pillaring solution was aged for the required time (5 to 25 minutes) with ultrasonic treatment at room temperature. The obtained $\mathrm{Al} / \mathrm{Zr}$ pillaring agent solution was set aside for use during the intercalation stage.

\section{Intercalation of Bentonite Clay}

The pillared clay catalysts were synthesized from South African bentonite clay following the method similar to that described by [5]. Ultrasonic treatment starting with dry clay material was used to prepare the pillared clay, in order to reduce material consumption and the number of steps involved with respect to the conventional method of preparation of pillared clays. In a typical preparation procedure for obtaining $\mathrm{Al} / \mathrm{Zr}$-pillared bentonites clay, the dry clay was added directly to the pillaring solutions to yield a $10 \mathrm{mmol}$ ratio of $(\mathrm{Al}+\mathrm{Zr}) / \mathrm{g}$ sodium bentonite $(25 \mathrm{~mL}$ pillaring solution $/ 1 \mathrm{~g})$ and stirred at room temperature for 30 minutes. The resulting suspensions were ultrasonicated for the required time $(5-20$ minutes) at $25^{\circ} \mathrm{C}$ to perform ion exchange, followed by 8 minutes of centrifugation. The collected solid was washed with high purity water (5 times with $200 \mathrm{ml}$ portions) to remove nitrates or chlorides (test with $\mathrm{AgNO}_{3}$ ), dried overnight in hot air oven at $120^{\circ} \mathrm{C}$, calcined at $500^{\circ} \mathrm{C}$ for $2 \mathrm{~h}$ in muffle furnace and grounded.

\section{Characterization Studies}

Powder x-ray powder diffraction (p-XRD) patterns were obtained by a high resolution Bruker AXS D8 X-ray advanced powder diffractometer with $\mathrm{CuK} \alpha$-radiation $(40 \mathrm{kV}, 40 \mathrm{~mA}$, $1.78897 \AA$ A) using a LinxEye detector. The XRD patterns were recorded with a step size of $0.02^{\circ}$ in the $2 \theta$ range of 5 to $80^{\circ}$ diffraction angle and using a standard speed with an equivalent counting time of 1 second per step. The specific surface area (SBET) calculated by the Brunauer-Emmett-Teller (BET) method was determined using the Micromeritics ASAP 2020 unit, which operates with physical adsorption of a monolayer of nitrogen gas (area $=0.162 \mathrm{~nm}^{2}$ ) at $-196^{\circ}$ and at a pressure of about $2 \mu \mathrm{mHg}$ for porosity measurement. The total pore volume (Vt) was estimated from the desorption data at $\mathrm{P} / \mathrm{P} 0$ values of $\sim 0.99$. Pore size distribution in the mesopore range was calculated using the Barrett-Joyner-Halenda (BJH) formula based on the desorption branch of the isotherms. The SEM imaging and analysis of the samples were recorded using a FEI Nova NanoSem 200 scanning electron microscope from FEI Company, equipped with the Energy-Dispersive X-ray (EDX) spectrometer and X-ray mapping for the determination of structural composition of the samples. 


\section{E. CWAO Experiments}

The experiments in the CWAO of phenol were carried out in a $350 \mathrm{ml}$ high-pressure autoclave "semi-batch type" reactor equipped with a magnetically driven stirrer ensuring desirable mass transfer, which had fittings to enable gas addition to the liquid phase and liquid sampling. The high-pressure autoclave was made of stainless steel manufactured by Parr Instruments Co., Moline, IL (model $4531 \mathrm{M}$ ) fitted with a removable glass lining. The reaction temperature was measured using a thermocouple and controlled by PID regulator. The autoclave reactor was charged with $200 \mathrm{ml}$ of $1000 \mathrm{mg} / \mathrm{L}$ phenol aqueous solution and $0.4 \mathrm{~g}$ of catalyst. The mixture inside the reactor was purged with pure nitrogen at $500 \mathrm{kPa}$ for 5 minutes to remove air in the reactor and the vessel was evacuated again to take out any remaining nitrogen from the reactor system. Thereafter, the reactor was heated to the desired reaction temperature $\left(100^{\circ} \mathrm{C}\right)$, with stirrer set at $800 \mathrm{rpm}$ to minimize the interfacial mass resistance between the gas and liquid phase and to ensure uniform temperature and concentration profiles in the liquid phase. The initial $\mathrm{pH}$ was adjusted to 3.0 with $1 \mathrm{M}$ $\mathrm{NaOH}$ or $\mathrm{HCl}$ solutions, which referred to the optimal $\mathrm{pH}$ range for $\mathrm{CWAO}$ process with $\mathrm{Al} / \mathrm{Zr}$ pillared clay catalysts and was selected based on the preliminary studies conducted. Once the temperature was reached, the mixture kept under vigorous stirring by additional 30 minutes in order to reach adsorption equilibrium. Next, pure oxygen of $500 \mathrm{kPa}$ was supplied to the reactor and the reaction was considered to "zero". However, before adding up pure oxygen, samples were taken to determine the amount of phenol removed by adsorption. The stirrer speed was set at $800 \mathrm{rpm}$ to ensure vigorous mixing, and the oxidation rate was not controlled by mass transfer effect. $5 \mathrm{ml}$ samples were periodically withdrawn during the reaction and immediately filtered by a nylon micro filter of $0.45 \mu \mathrm{m}$ pore size. In the entire process, the reaction system was kept under isobaric and isothermal conditions.

\section{F. Analysis of Phenol Concentration}

The concentrations of phenol in the liquid samples were analyzed by HPLC method with an ODS-3 column and a UV detector (LC-10AD, Shimadzu, Kyoto, Japan). The chromatograph was calibrated with standard solutions. A mixture of $60 / 40(\mathrm{~V} / \mathrm{V})$ of methanol to water (slightly acidified $/ 0.1 \%$ acetic acid was added) was used as a mobile phase, with $254 \mathrm{~nm}$ as the detection UV absorbance wavelength for phenol analysis. For all compounds, the flow rate of the mobile phase was $1 \mathrm{ml} / \mathrm{min}$. The column was operated at a constant temperature of $30^{\circ} \mathrm{C}$. Prior to injection into the analytical HPLC column, the samples were filtered in order to remove any contained solid particles.

\section{RESULTS AND DISCUSSION}

\section{A. Characterization of Al/Zr-Pillared Bentonites}

The HRSEM images of the South African bentonite and the pillared bentonite clay samples with untrasonication times of 5 , 10 and 20 minutes are shown in Fig. 1. Some differences are observed in the surface structure of the raw bentonite compared with the pillared bentonite as a result of the pillaring process. The raw bentonite exhibits a typical layered structure with smooth surface (Fig. 1a). The HRSEM images show that increasing the ultrasonic treatment time results in a small tightly packed pattern with highly porous and rough surface (Fig. 1b-d). The result of chemical analyses of the raw bentonite and pillared bentonite shown in Table I indicates a successful improvement of pillaring cations in bentonite clay. The high content of $\mathrm{Na}$ content indicates that the raw bentonite clay is in the $\mathrm{Na}^{+}$form. While the decrease in the amounts of exchangeable $\mathrm{Na}^{+}$and $\mathrm{Ca}^{2+}$ cations confirms the insertion of Keggin ion between the bentonite layers. The high $\mathrm{Si} / \mathrm{Al}$ content in all pillared bentonite samples indicates the presence of quartz and muscovite as also confirmed by XRD.

TABLE I: CHEMICAL ANALYSIS OF NATURAL AND PILLARED BENTONITES.

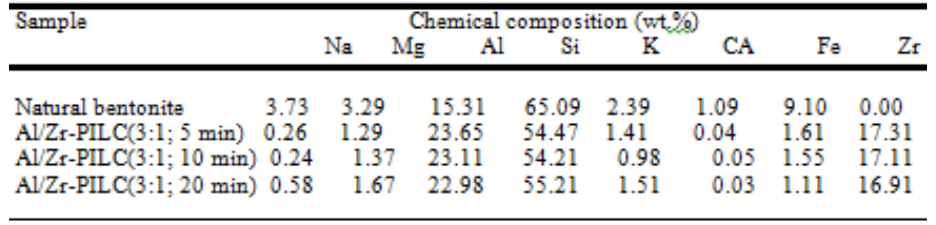
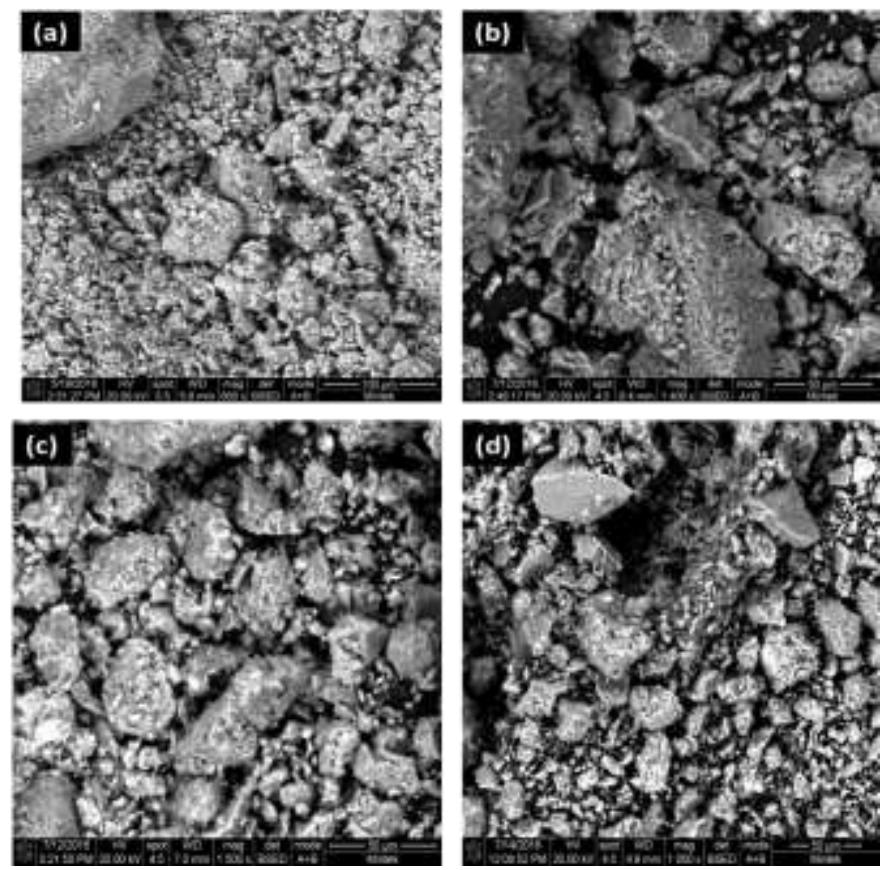

Fig. 1. SEM images of the different bentonite samples: (a) Natural bentonite clay, (b) Al/Zr-PILC (3:1, $5 \mathrm{~min}$ ), (b) Al/Zr-PILC (3:1, 10 min), (b) Al/Zr-PILC (3:1, $20 \mathrm{~min})$.

The XRD patterns of raw bentonites and $\mathrm{Al} / \mathrm{Zr}$-pillared bentonites are shown in Fig. 2. While the basal spacing $\left(\mathrm{d}_{001}\right)$ values are listed in Table II. The patterns of South African bentonite and pillared bentonite are consistent with the pattern reported in other studies focused on the use of ball milled South African bentonite clay for neutralization and attenuation of inorganic contaminants from acidic mine water and preparation of Fe, Zn, Al-pillared montmorillonite catalyst for catalytic wet peroxide oxidation of Orange II dye [15, 21]. As 
shown in Fig. 2 montmorillonite, quartz, muscovite and calcite were observed to be the mineral phases which are present in raw bentonite clay matrices. The $\mathrm{Al} / \mathrm{Zr}$-pillared bentonite clay also contained montmorillonite, quartz, muscovite and calcite. This indicates that the crystalline structure of the starting bentonite clay was not strongly affected by the pillaring process. However, a closer analysis of the XRD patterns $\left(\mathrm{d}_{001}, 2\right.$ theta $=6^{\circ}$ ) indicates that Na-montmorillonite pillared clay intensity of Na-montmorillonite peak becomes weaker with increasing ultrasound treatment time and retained its XRD peak up to 10 minutes ultrasound treatment. Thus, suggesting that the best results were obtained with the shortest ultrasound treatments time as the increase in ultrasound treatment time resulted in a loss of regularity in the layer structure. As shown in Table II the basal spacing $\left(\mathrm{d}_{001}\right)$ of starting raw bentonite clay $(1.56 \mathrm{~nm})$ increases to 1.84 to $1.91 \mathrm{~nm}$ for pillared bentonite clay, thus, indicating that the pillaring process has occurred/successful introduction of active metal to Keggin structure by cation exchange process. Therefore, the ultrasound treatment through direct addition of dry clay to pillaring solution provides a novel route to overcome the disadvantages of conventional pillaring and ion exchange method. This observation is supported by Tomul, [5], who reported the preparation of $\mathrm{Fe} / \mathrm{Cr}$-pillared bentonite by adding dry clay to the pillaring solution directly.

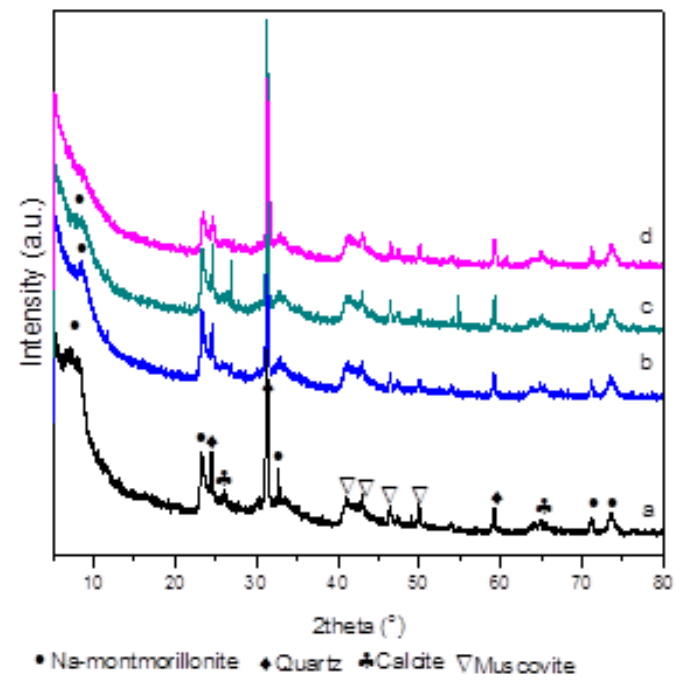

Fig. 2. X-ray diffraction patterns of the different bentonite samples: (a) Natural bentonite clay, (b) Al/Zr-PILC (3:1, 5 min), (c) Al/Zr-PILC (3:1, $10 \mathrm{~min})$, (d) Al/Zr-PILC (3:1, $20 \mathrm{~min})$.

The BET surface areas and pore volumes of the raw bentonite and $\mathrm{Al} / \mathrm{Zr}$ pillared bentonites are presented in Table II. Pillaring of raw bentonite leads to an increase in specific surface area and pore volumes. These results are in agreement with the XRD results which confirmed successful pillaring of the raw bentonite clay. The higher specific surface area indicates that the prepared $\mathrm{Al} / \mathrm{Zr}$ pillared bentonites have a microporous structure. The specific surface areas are the highest for the pillared bentonites clay prepared for 5 and 10 min ultrasound treatment time. Further increase in ultrasound treatment time results in a decrease of specific surface area, this supporting the results obtained by XRD. Therefore, these results suggest that the $\mathrm{Al} / \mathrm{Zr}$-PILC $(3: 1 ; 10$ minutes) catalyst with higher specific surface area may exhibit better CWAO activity.

TABLE II: SURFACE PROPERTIES OF PREPARED CATALYSTS AND RAW BENTONITE CLAY.

\begin{tabular}{|c|c|c|c|c|}
\hline Sample & $\left(\mathrm{m}^{2} / \mathrm{g}\right)$ & $\mathrm{V}_{0.99}^{2}\left(\mathrm{~cm}^{3} / \mathrm{g}\right)$ & $\mathbf{V}_{\text {mic }}^{3}\left(\mathrm{~cm}^{3} / \mathbf{g}\right)$ & $\mathrm{d}^{4}{ }_{001}(\mathrm{~nm})$ \\
\hline Natural bentonite & 61 & 0.105 & 0.009 & 1.56 \\
\hline $\mathrm{Al} / \mathrm{Zr}-\operatorname{PILC}(3: 1 ; 5 \mathrm{~min})$ & 190 & 0.166 & 0.014 & 1.91 \\
\hline $\mathrm{Al} / \mathrm{Zr}-\operatorname{PILC}(3: 1 ; 10 \mathrm{~min}$ & 1) 199 & 0.171 & 0.018 & 1.90 \\
\hline $\mathrm{Al} / \mathrm{Zr}-\mathrm{PILC}(3: 1 ; 20 \mathrm{~min}$ & 1) 185 & 0.148 & 0.010 & 1.84 \\
\hline
\end{tabular}

${ }^{1}$ Specific surface area $\left(\mathrm{S}_{\mathrm{BET}}\right) ;{ }^{2}$ Total pore volume at $\mathrm{p} / \mathrm{p}^{0} \sim 0,99 ;{ }^{3}$ Micropore volume; ${ }^{4}$ Basal spacing

\section{B. Effect of Ultrasonic Time on Catalytic Activity of Al/Zr-Pillared Bentonite}

The results of the catalytic activity of $\mathrm{Al} / \mathrm{Zr}$-pillared bentonite in the wet air oxidation of phenol reaction are shown in Fig. 3. In order to prove that $\mathrm{Al} / \mathrm{Zr}$ active phase is responsible for the conversion of phenol, control catalytic experiment was carried out in the presence of raw bentonite clay. It was found that raw bentonite clay exhibited a very low catalytic activity, this might be attributed to the absence of active sites (Al/Zr active phase). The Al/Zr-PILC $(3: 1 ; 10$ minutes) catalyst exhibited the best catalytic performance with complete conversion of phenol in an hour of reaction of time. While the Al/Zr-PILC (3:1; 5 minutes) and Al/Zr-PILC (3:1; 20 minutes) also exhibited excellent catalytic activity, however, lower than that of Al/Zr-PILC $(3: 1 ; 10 \mathrm{~min})$. As shown in Fig.3 $\mathrm{Al} / \mathrm{Zr}-\mathrm{PILC}(3: 1 ; 5$ minutes) and Al/Zr-PILC (3:1; 20 minutes) achieved 90 and $80 \%$, respectively, after an hour of reaction time. Therefore, the effect of ultrasound treatment time in both formation of pillaring solutions and intercalation stage shows no significant differences in terms of catalytic activity, however, the Al/Zr-PILC ultrasonically treated for 5 or 10 minutes performed slightly better than those treated for 20 minutes. These results are can be correlated with the results obtained in the XRD and BET surface area analysis, according to these results the stable structure and the proper number of active sites and their distribution on the surface of the catalyst is significant for excellent catalytic activity.

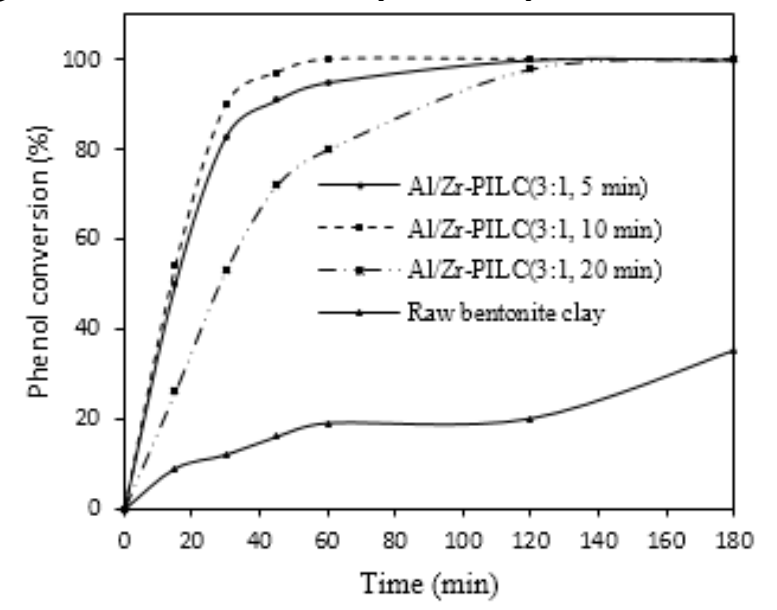

Fig.3. Effect of ultrasonic preparation time on catalytic activity of the PILCs in the oxidation of phenol (reaction conditions: $200 \mathrm{ml}$, $1000 \mathrm{mg} / \mathrm{L}, 0.4 \mathrm{~g}, \mathrm{pH} 3.0,100^{\circ} \mathrm{C}$ ). 


\section{Chemical Stability and Reusability of the Al/Zr-Pillared Bentonite}

The development in the green technologies and management practices for environmental benefit involves catalyst lifetime. This is a significant parameter in the industrial wastewater treatment processes, due to the fact that its use for a longer period leads to a significant cost reduction of the whole industrial wastewater treatment process. The Al/Zr-PILC (3:1; 10 minutes) catalyst, which displayed the best catalytic performance, was selected for the reusability studies. The catalyst was recycled five times to investigate the number of times it can be reused after each cycle. After successful removal of phenol by the CWAO, the catalyst was recovered by separating the $\mathrm{Al} / \mathrm{Zr}$-PILC $(3: 1 ; 10$ minutes) solids from the liquid phase and then added into $100 \mathrm{~mL}$ of $\mathrm{CaCl}_{2}$ solution (4\%) and stirred for 120 minutes at room temperature and then rinsed with high purity water. After regeneration, the catalyst was air-dried in the oven at $120^{\circ} \mathrm{C}$ for 5 hours and used to study its reusability. It was found that total conversion of phenol obtained after 1 hour by fresh Al/Zr-PILC (3:1; 10 minutes) was preserved even after 4 runs, and decrease to $89 \%$ in the fifth catalytic run. However, the oxidation efficiency of phenol was still significant after five times of reuse. Deposition of phenol on the surface of the Al/Zr-PILC (3:1; 10 minutes) catalyst after each cycle of CWAO can be a possible cause of the observed decrease on the oxidation efficiency of phenol. This might due to the fact that each time the catalyst is reused new parts of the catalyst surface become unavailable for phenol adsorption. These results indicate that the Al/Zr-PILC (3:1; 10 minutes) was sufficiently stable and exhibit higher reusability without a significant loss in its catalytic activity. Therefore, it can be concluded that the reusability of Al/Zr-PILC $(3: 1 ; 10$ minutes) in the oxidation of phenol goes towards green chemistry key principles.

\section{CONCLUSION}

The preparation of pillared South African bentonite clay exhibiting $\mathrm{Al} / \mathrm{Zr}$-mixed pillars by direct addition of the bentonite clay to the pillaring solution using ultrasound treatment during the formation of the pillaring solution and in the intercalation process was successful. The results demonstrated that $\mathrm{Al} / \mathrm{Zr}$-pillared bentonite catalyst can be successfully prepared from South African bentonite clay by ultrasound treatment without the need for Na-exchange before pillaring process. The HRSEM-EDS analysis reveals that there are no significant differences in terms of physicochemical properties of the prepared $\mathrm{Al} / \mathrm{Zr}$-pillared bentonite catalysts at different ultrasound treatment time. The XRD analysis results confirmed the successful introduction of $\mathrm{Zr} / \mathrm{Al}$ polyhydroxycations into the interlayers of bentonite clay with increasing basal spacing $\left(\mathrm{d}_{001}\right.$-value $)$. The obtained $\mathrm{Zr} / \mathrm{Al}$-pillared bentonite exhibited higher BET surface area and pore volumes compared to starting bentonite material. However, generally best results are obtained with short ultrasound treatment times, while the increase in ultrasound treatment resulted in a decrease in surface area and pore volumes associated with a loss of regularity of the Al/Zr-pillared bentonite clay. The effect of ultrasound treatment time has a minor effect on the physiochemical properties of $\mathrm{Al} / \mathrm{Zr}$-pillared bentonite clay but observable effect on the catalytic activity of phenol conversion. The $\mathrm{Al} / \mathrm{Zr}$-pillared bentonite clay with the shortest ultrasound treatment times performed slightly better than the longest ultrasound treatment time. In comparison with the conventional method, the low water usage, reducing preparations steps, reusability and the advantageous reduction of preparation time without losing catalytic activity in this study will provide industrial production advantages in $\mathrm{Al} / \mathrm{Zr}$-pillared bentonite clays. Moreover, ultrasonic treatment method reduces both the preparation of pillaring solution and intercalation steps time from 24 hours to 5-20 minutes. Therefore, this study suggested that $\mathrm{Al} / \mathrm{Zr}$-pillared bentonite can be used as a potentially effective phenol conversion catalyst for practical applications.

\section{ACKNOWLEDGMENTS}

This research was financially supported by the National Research Foundation (NRF)/ Department of Science and Technology (DST) of South Africa under Professional Development Programme (PDP) Project No. 96719 and Mineral Science Council of South Africa (Mintek) under CWO of Wastewater Project No. ADR 31802.

\section{REFERENCES}

[1] H.S. Bamufleh, M.M.B. Noureldin, M.M. El-Halwagi, Sustainable process integration in the petrochemical industries, in: Petrochemical Catalyst Materials, Processes, and Emerging Technologies, IGI Global, 2016, pp. 150-163.

[2] E.S.Z. El-Ashtoukhy, Y.A. El-Taweel, O. Abdelwahab, E.M. Nassef, Treatment of petrochemical wastewater containing phenolic compounds by electrocoagulation using a fixed bed electrochemical reactor, Int. J. Electrochem. Sci, 8 (2013) 1534-1550.

[3] E. Guélou, J. Barrault, J. Fournier, J.-M. Tatibouët, Active iron species in the catalytic wet peroxide oxidation of phenol over pillared clays containing iron, Applied Catalysis B: Environmental, 44 (2003) 1-8.

[4] A. Eftaxias, J. Font, A. Fortuny, A. Fabregat, F. Stüber, Catalytic wet air oxidation of phenol over active carbon catalyst: global kinetic modelling using simulated annealing, Applied Catalysis B: Environmental, 67 (2006) 12-23.

[5] F. Tomul, The effect of ultrasonic treatment on iron-chromium pillared bentonite synthesis and catalytic wet peroxide oxidation of phenol, Applied Clay Science, 120 (2016) 121-134.

[6] A. Babuponnusami, K. Muthukumar, A review on Fenton and improvements to the Fenton process for wastewater treatment, Journal of Environmental Chemical Engineering, 2 (2014) 557-572.

[7] S. Malato, J. Blanco, A. Vidal, C. Richter, Photocatalysis with solar energy at a pilot-plant scale: an overview, Applied Catalysis B: Environmental, 37 (2002) 1-15.

[8] A. Rubalcaba, M.E. Suárez-Ojeda, F. Stüber, A. Fortuny, C. Bengoa, I. Metcalfe, J. Font, J. Carrera, A. Fabregat, Phenol wastewater remediation: advanced oxidation processes coupled to a biological treatment, Water science and technology, 55 (2007) 221-227.

[9] J. Levec, A. Pintar, Catalytic wet-air oxidation processes: a review, Catalysis Today, 124 (2007) 172-184.

[10] Y.I. Matatov-Meytal, M. Sheintuch, Catalytic abatement of water pollutants, Industrial \& engineering chemistry research, 37 (1998) 309-326. 
[11] A. Alejandre, F. Medina, X. Rodriguez, P. Salagre, Y. Cesteros, J.E. Sueiras, $\mathrm{Cu} / \mathrm{Ni} / \mathrm{Al}$ layered double hydroxides as precursors of catalysts for the wet air oxidation of phenol aqueous solutions, Applied Catalysis B: Environmental, 30 (2001) 195-207.

[12] L.F. Liotta, M. Gruttadauria, G. Di Carlo, G. Perrini, V. Librando, Heterogeneous catalytic degradation of phenolic substrates: catalysts activity, Journal of Hazardous Materials, 162 (2009) 588-606.

[13] F. Bergaya, G. Lagaly, Developments in clay science, Handbook of Clay Science, vol. 5, in, Elsevier, Oxford, UK, 2013.

[14] S. Zhou, C. Zhang, X. Hu, Y. Wang, R. Xu, C. Xia, H. Zhang, Z. Song, Catalytic wet peroxide oxidation of 4-chlorophenol over Al-Fe-, Al-Cu-, and Al-Fe-Cu-pillared clays: Sensitivity, kinetics and mechanism, Applied Clay Science, 95 (2014) 275-283.

[15] W. Ye, B. Zhao, H. Gao, J. Huang, X. Zhang, Preparation of highly efficient and stable $\mathrm{Fe}, \mathrm{Zn}, \mathrm{Al}$-pillared montmorillonite as heterogeneous catalyst for catalytic wet peroxide oxidation of Orange II, Journal of Porous Materials, 23 (2016) 301-310.

[16] M. Ding, S. Zuo, C. Qi, Preparation and characterization of novel composite $\mathrm{AlCr}$-pillared clays and preliminary investigation for benzene adsorption, Applied Clay Science, 115 (2015) 9-16.

[17] C.B. Molina, J.A. Casas, A.H. Pizarro, J.J. Rodriguez, Pillared clays as green chemistry catalysts: application to wastewater treatment, Clay: Types, Properties and Uses, (2011) 435-474.

[18] M. Stanisavljević, L. Nedić, Removal of phenol from industrial wastewaters by horseradish-Cochlearia armoracia L-peroxidase, Facta universitatis-series: Working and Living Enviromental Protection, 2 (2004) 345-349.

[19] A. Gil, L.M. Gandia, M.A. Vicente, Recent advances in the synthesis and catalytic applications of pillared clays, Catalysis Reviews, 42 (2000) 145-212.

[20] D. Fu, F. Zhang, L. Wang, F. Yang, X. Liang, Simultaneous removal of nitrobenzene and phenol by homogenous catalytic wet air oxidation, Chinese Journal of Catalysis, 36 (2015) 952-956.

[21] V. Masindi, M.W. Gitari, H. Tutu, M. DeBeer, Efficiency of ball milled South African bentonite clay for remediation of acid mine drainage, Journal of Water Process Engineering, 8 (2015) 227-240.

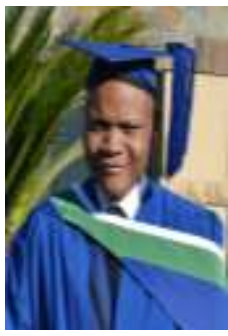

S.J Baloyi is currently working as a Pre Doctoral Fellow in the Advanced Materials Division (AMD), Mintek, South Africa and is pursuing his $\mathrm{PhD}$ in Catalysis from Witwatersrand University, South Africa. He is doing his doctoral work under the guidance of Dr T.A Ntho and Dr J.A Moma. He obtained his Master of Technology (2015), Bachelor of Technology (2012) and National diploma (2011) in Chemical engineering from Vaal University of Technology, South Africa. His current research interests include environmental pollutants and their cutting edge removal technologies, the design and synthesis of novel catalysts for water and wastewater treatment. 